\title{
Rescatar el Pasado, Activar el Turismo - Reflexiones en Torno a la Gestión Patrimonial
}

\author{
Marcela Brac \\ Universidad de Buenos Aires, Buenos Aires, Cidade Autônoma de Buenos Aires, \\ Argentina \\ E-mail: marcelabrac@gmail.com
}




\section{Resumen}

En este artículo pretendo reflexionar sobre el proceso de patrimonialización de memorias en relación a iniciativas turísticas impulsadas por políticas públicas. A tales fines examino la relación entre poder político provincial y sociedad civil en torno a la valorización y consumo del pasado. En el marco de políticas públicas que incentivan la activación patrimonial con fines económicos analizo la conformación del museo comunitario de Villa Guillermina, como recurso estratégico de gestión local, y a la vez como institución que contribuye a estructurar memorias colectivas que visibilizan a determinados grupos sociales, e invisibilizan a otros.

Palavras-chave: Recuerdos. Poderes Públicos. Museo. Patrimonio. Turismo.

\section{Resumo}

Neste artigo pretende-se refletir sobre o processo de patrimonialização de memórias em relação às iniciativas de turismo impulsionadas por politicas públicas. Para tais fins, examina-se a relação entre o poder político provincial e a sociedade civil em torno da valorização $e$ do consumo do passado. No âmbito das políticas públicas que incentivam a ativação econômica para fins econômicos, analisa-se a conformação do museu comunitário Villa Guillermina, como recurso estratégico para a gestão local $e$, ao mesmo tempo, uma instituição que contribui para a estruturação de memórias coletivas que tornam visíveis certos grupos sociais, e invisibilizam outros.

Keywords: Memórias. Poderes Públicos. Museu. Patrimônio. Turismo. 


\section{Introducción}

T a intención en este análisis es abordar la memoria colectiva desde Luna perspectiva constructivista, así que mi interés se centra en el proceso de selección de recuerdos y elaboración de sentidos que se atribuyen al pasado, y en los propósitos y motivaciones que en el presente orientan la agencia de los actores sociales. En esta línea retomo el planteo de Jelin (2002), de la memoria como objeto de trabajo elaborativo de sentidos del pasado, en el que algunos grupos sociales, emprendedores de memoria, juegan un papel decisivo. En este caso, y en el contexto de actividades turísticas emergentes analizo la conformación del museo de Villa Guillermina como espacio social institucionalizado con el propósito de comunicar a "otros", los visitantes, experiencias y memorias compartidas por una comunidad. Asimismo, examino la conformación de museo como dispositivo que posibilita enunciar y legitimar algunas versiones del pasado, y silenciar y/o abreviar ${ }^{1}$ otras.

En la primera década del presente siglo, concretamente a partir del año 2004, el gobierno de la provincia de Santa Fe, Argentina, a través de la Subsecretaría de Turismo comenzó a incentivar la creación de una ruta turística con el propósito de unir algunas poblaciones situadas en la Cuña Boscosa santafesina, subregión Chaco santafesino, advirtiendo la potencialidad de recursos vinculados al pasado industrial de la zona.

Para abordar este tema considero necesario tener presente algunos aspectos históricos que remiten a la formación de asentamientos poblacionales en la zona de estudio, y a las modalidades de producción que aseguraron la reproducción social de las personas. El conocimiento de éstos antecedentes históricos nos permitirá aproximarnos a la comprensión de la emergencia del fenómeno turístico en la región. 
Y a entender por qué un pasado vivido por algunos, después de tanto tiempo se transforma en un pasado exhibido para otros.

\section{El Tiempo de Trabajo}

En el último cuarto del siglo XIX, simultáneamente al avance del ejército argentino sobre los territorios de pobladores originarios se produce la penetración capitalista en lo que luego se denominará Chaco santafesino. Villa Guillermina al igual que otras poblaciones situadas en la Cuña Boscosa santafesina, subregión del Chaco santafesino, surgió a inicios del siglo XX como pueblo fábrica vinculado a la explotación foresto - industrial ${ }^{2}$, y a una empresa extranjera en particular, La Forestal.

En la configuración histórico social del Chaco santafesino se identifican dos formas diferenciales de asentamiento poblacional. Por un lado, el poblamiento de la zona boscosa se vincula a la demanda de mano de obra de la industria forestal que estimuló flujos migratorios internos, principalmente regionales; por otro lado, en la llanura este de la subregión apta para la agricultura, se formaron las primeras colonias agrícolas con inmigrantes europeos.

Entonces, en términos generales se puede afirmar que para los primeros años del siglo XX en el Chaco santafesino predominaron dos modelos de poblamiento asociados con actividades productivas diferenciales y no vinculadas. Migrantes internos, criollos, llegaron a la zona boscosa atraídos por la oferta del capital forestal, trabajadores que a su vez poblaron y dieron identidad a los primeros asentamientos forestales. En tanto que migrantes europeos, gringos, incentivados por políticas estatales de poblamiento formaron las primeras colonias agrícolas del Chaco santafesino.

En síntesis, criollos y gringos pertenecieron a universos que se identificaron por las actividades laborales y contribuyeron a construir el perfil productivo de la subregión, a la vez fueron configurando sentidos de pertenencia e identidad. Esto es, formas particulares de ser y de estar en el territorio.

En el área boscosa, la penetración del capital forestal fue generando las condiciones necesarias para el poblamiento de la zona. 
Villa Guillermina surgió como un pueblo fábrica o para retomar una categoría nativa, pueblo forestal, y funcionó como un universo singular atravesado por la dinámica del trabajo fabril hasta el cierre de la fábrica de tanino en el año 1952.

La Forestal controló la totalidad del proceso productivo desde la fase extractiva de materia prima hasta la elaboración de tanino, también la comercialización del producto en el mercado internacional, y además ejerció en sus dominios territoriales el control de los medios de comunicación y transporte. En la década de los años treinta del siglo pasado, durante el auge de la industria tánica, en Villa Guillermina habitaban alrededor de cinco mil personas, todas ellas dependientes del trabajo que proporcionaba la empresa. Se estima que el número de trabajadores rurales, obrajeros ${ }^{3}$, dedicados a las actividades extractivas de materia prima superaba ampliamente a los trabajadores de fábrica (Gori, 1974).

La política empresarial mantuvo practicas diferenciales en la organización del trabajo fabril y extractivo y en el alcance de beneficios laborales. El trabajo del obraje en el monte ${ }^{4}$ consistía en la tala de árboles de quebracho colorado, y la preparación de la madera para el proceso industrial. El obraje no se encontraba tecnificado, lo que implicó trabajo intensivo y carencia de todo tipo de protección laboral. Además, los trabajadores rurales fueron sometidos a un sistema de endeudamiento, que consistía en la venta anticipada de bienes necesarios para la vida cotidiana, a precios exorbitantes, que luego eran descontados del jornal. Por medio de este mecanismo, administrado generalmente por contratistas dependientes de la empresa, los trabajadores contraían deudas que los obligaban a continuar trabajando para la empresa. Por el contrario, la modalidad implementada para retener la mano de obra fabril fue la provisión de viviendas, servicios públicos, y actividades de ocio recreativas y culturales.

Para sintetizar, la industria del tanino revistió el formato de enclave productivo (Bitlloch; Sormani, 1997) liderado por la empresa extranjera, La Forestal. La paralización de la industria tánica implicó cierre definitivo de fábricas y desmantelamiento de la plataforma extractiva de materia prima. El proceso de desinversión de capital 
(Balazote et al., 2009) forestal provocó la violenta desarticulación de la comunidad ocupacional (Eckert, 2012), y generó el éxodo de trabajadores - pobladores que se habían asentado en la zona boscosa del Chaco santafesino.

Las poblaciones que no desaparecieron como consecuencia de la crisis productiva permanecieron en situación de estancamiento económico, y quedaron en situación de marginalidad respecto de las poblaciones de origen agrícola que continuaron desarrollándose e impulsando la dinámica económico productiva del norte santafesino.

Desde el colapso de la industria tánica, la adjetivación forestal dejó de funcionar como indicador de la actividad laboral que caracterizaba a una comunidad ocupacional, los forestales.

Luego de la paralización industrial los pueblos forestales comenzaron a ser identificados como "pueblos fantasmas". Con esta expresión metafórica se buscó expresar la muerte de las poblaciones por la desaparición del trabajo, en otras palabras, fue una forma de expresar la nueva situación económica y social de los centros poblacionales que habían vivido exclusivamente vinculados a la industria del tanino. Y aunque fue una nominación siempre resistida por los pobladores locales tuvo amplia difusión, principalmente a través de los medios de comunicación, y pasó a formar parte del imaginario colectivo.

\section{El Tiempo del Patrimonio}

En la primera década del presente siglo y por iniciativa de la administración pública provincial comienza a diseñarse un plan turístico para los pueblos de origen forestal, con el propósito de contribuir al desarrollo de la economía regional. Esta propuesta implicó la proyección de un producto turístico que se denominó "La ruta del tanino - pueblos forestales". Este tipo de intervención resulta coherente con lo que Aguilar Criado (2005) identifica a nivel internacional bajo el formato de, diseños de políticas turísticas que contemplan los elementos patrimoniales como recursos turísticos comercializables. De este modo, a través del formato de ruta turística se pretende comercializar un territorio completo bajo un denominador común (Hernández Ramírez, 2011). 
En este contexto, Villa Guillermina y otras localidades que estuvieron vinculadas a la industria tánica comenzaron a posicionarse como potenciales destinos turísticos. A diferencia del tiempo pasado en el presente el calificativo forestal no es indicador de la actividad productiva generadora de empleo, por el contrario, sirve para denotar la singularidad del pasado de una comunidad. En otras palabras, ya no se trata del trabajo, sino del recuerdo del trabajo lo que cobra relevancia en este nuevo contexto social

El Estado provincial, con el objetivo de activar economías regionales, comienza a producir discursos valorativos en relación a lo patrimonial, y asume una posición protagónica en la iniciativa de promoción turística. En tal sentido introduce como nueva propuesta turística a nivel provincial, pueblos forestales.

[...] Santa Fe es historia: Santa Fe cuenta con un patrimonio cultural procedente de los desarrollos arquitectónicos, ferroviarios, ganaderos e industriales, así como el legado por los acontecimientos históricos, políticos y sociales. [...] Capital de la 'Cuña Boscosa': Las localidades de Villa Guillermina, Villa Ana, Tartagal y La Gallareta, al norte de la capital provincial se formaron para la explotación del quebracho colorado, árbol utilizado para fabricar durmientes para el ferrocarril y para la explotación de tanino. El corredor une estas poblaciones en un recorrido histórico por lo que fuera uno de los asentamientos de las grandes empresas inglesas en el norte provincial a principios del 1900 'La Forestal'. ( Sitio Oficial del Gobierno de la Provincia de Santa Fe, 2007)

En consecuencia, a partir del año 2004 comenzó a construirse la nominación de pueblos forestales asociada al turismo cultural. Es importante resaltar que la intervención del poder público provincial fue dando identidad a la nueva ruta turística que se pretendía promocionar, tornando las construcciones edilicias del pueblo fábrica, como así también las memorias del tiempo pasado en elementos centrales del atractivo turístico cultural. Además, la injerencia del poder público extra local generó en la sociedad reacciones positivas, que se advierten en los niveles de movilización y organización en torno a la cuestión del pasado, la recuperación de memorias y la formación de un museo comunitario. 
En ese marco surgió la necesidad gestar una institución local que actuara como articuladora entre el poder político provincial y la comunidad, y a la vez como entidad canalizadora de proyectos locales vinculados al fenómeno de promoción turística.

En efecto, la intervención de la administración pública provincial no es menor, porque operó de guía orientadora para el armado del proyecto turístico local, señalando la potencialidad de transformar la singularidad del pasado comunitario y la cultura en producto para el mercado turístico. Además, y como veremos más adelante, el Estado se instituye en agente financiador de un emprendimiento local.

Así, a partir de la intervención del poder púbico algunos pobladores actuaron como dinamizadores del proyecto turístico, con el apoyo de la comunidad conformaron una comisión que al poco tiempo se transformó en Asociación de Rescate de la Cultura Forestal. La institución actuó como articuladora entre Estado y comunidad, a la vez que se consolidó en el rol de gestora de emprendimientos vinculado a la valorización del pasado y de los referentes patrimoniales. En el siguiente relato uno de los miembros fundadores de la institución señala los propósitos que impulsaron la formación del museo comunitario:

La idea de un museo surge porque en algún momento la provincia empezó a mirar a estos pueblos con la posibilidad de hacer algo de turismo cultural para dar una ayuda. [...]. En el 2004 vino el secretario de cultura y nos convocó y fue muy categórico. Nos dijo: 'ustedes tienen un patrimonio vivo, hay otros lugares donde solo hay ruinas, ustedes acá tienen los edificios en pie. Pero no nos pidan a nosotros lo que tienen que hacer ustedes'. Así que asumimos el desafío y empezamos a trabajar para elaborar un proyecto, y lo presentamos en la Secretaría de Cultura [... ]. (Integrante de la Asociación de Rescate de la Cultura Forestal, 2005)

Aprovechando la visibilidad que comenzó a cobrar en la escena local y regional los pueblos forestales, por medio del incentivo del poder político provincial, la Asociación generó un nuevo proyecto vinculado a la actividad turística cultural de perfil escolar.

[...] Nosotros presentamos el proyecto en la Secretaría de Cultura en Santa Fe para la creación del Campamento Cultural, siempre hacemos hincapié en el turismo cultural, 
porque hablar de turismo de caza o pesca es otra cosa y nuestros recursos son escasos. Nosotros lo que queremos es aprovechar lo que quedó de la historia de La Forestal, potenciarla y ofrecerla como turismo, esa es la idea. (Integrante de la comisión ejecutiva de la Asociación, 2005)

Para este proyecto la Asociación retoma la modalidad institucional "Campamento Cultural" vigente en la provincia de Santa Fe, que consiste en una propuesta orientada a la educación artística integral que posibilita

[...] experiencias de convivencias con la historia local, generando herramientas fundamentales para el desarrollo de la sensibilidad y la formación de ciudadanos activos, creativos y solidarios. (Ministerio de Innovación y Cultura de la Provincia de Santa Fe, 2007)

En este sentido la creación del Campamento Cultural "Corazón de Quebracho" en Villa Guillermina fue una apuesta estratégica de la Asociación, porque logró involucrar al Estado provincial como inversor y garante de la continuidad del emprendimiento educativo, inserto en un proyecto más amplio que abarca la promoción turística. En este sentido, con la creación del Campamento Cultural la administración pública, el Estado provincial, se constituye en empleador de las personas que trabajan en la institución y garantiza de ese modo la continuidad del emprendimiento turístico local.

El Campamento Cultural Corazón de Quebracho fue diseñado por un grupo de pobladores integrantes de la Asociación de Rescate de la Cultura Forestal. La propuesta base del proyecto fue incentivar el turismo cultural escolar, cuyo eje central gira en torno al conocimiento del pasado industrial y de la cotidianeidad de los pueblos forestales. El Campamento fue creado en el año 2005 por medio de un Decreto de poder Ejecutivo provincial, y comenzó a funcionar en el año 2006, como se mencionó reviste la categoría de escuela artística provincial dependiente del Ministerio de Innovación y Cultura.

En síntesis, el Campamento Cultural se promociona como oferta educativa y turística a la vez, porque convoca a estudiantes de la provincia a la realización de un viaje de estudio temático. Desde su 
inauguración en el año 2006 hasta el presente recibe semanalmente grupos de estudiantes provenientes principalmente de escuelas de la zona. La actividad nunca se vio interrumpida por falta de visitantes, aún más, muchas escuelas hacen reservas con antelación de hasta un año dado la alta demanda de vacantes, lo que da cuenta de la efectividad que alcanzó el proyecto.

Si bien la propuesta inicial de activación del patrimonio se gestó en la escena extra local es en el entorno local donde se produce su realización, de acuerdo a las posibilidades e intereses de la población. En otras palabras, un proyecto gestado por la administración pública en el escenario extra local recién se torna viable cuando involucra y posibilita la participación activa de los actores sociales locales, de esto dependerá en gran medida la concreción y sostenimiento de emprendimientos vinculados a la activación patrimonial.

La administración provincial propuso la creación de una ruta turística para vincular varias poblaciones en un mismo atractivo, pretendiendo incentivar inversiones locales y regionales para el desarrollo de infraestructura turística, lo que a su vez "[...] supone una visión instrumental del territorio y su patrimonio concebidos como recursos que pueden transformarse [...] en productos turísticos" (Hernández Ramírez, 2011, p. 230).

Sin embargo, hasta el presente ningún inversor local ha derivado recursos económicos en esta actividad que hasta el momento se expresa, a excepción de Villa Guillermina, en términos potenciales. Por otro lado, y confirmando lo mencionado, resulta interesante señalar que es el Estado provincial el que se ha convertido en inversor y financiador de la activación turística en la única localidad que puso en marcha un programa de perfil turístico vinculado a la valorización del pasado forestal.

En síntesis, en el presente la Ruta del tanino - pueblos forestales expresa la potencialidad del lugar, pero aún no ha logrado generar impulso turístico propio. Sin embargo, no hay que restarle importancia al tema, porque en términos turísticos ha quedado instalado como sitio de interés a nivel regional y provincial, puntualmente para el turismo identificado como histórico cultural, y en este proceso la intervención 
del poder público ha sido decisivo como agente de promoción, difusión, e inversión, y continúa siéndolo.

La visibilidad que cobraron los pueblos forestales, en los últimos años, y Villa Guillermina en particular, está asociada a la intervención del Estado provincial y la emergencia de la actividad turística cultural de perfil escolar. En esta coyuntura favorable se intenta revertir la imagen de "pueblo fantasma", asociada a devastación de recursos naturales, pobreza, y postergación económica. En términos simbólicos el pasaje de pueblo fantasma a pueblo forestal, representa para los pobladores la oportunidad de lograr visibilidad positiva, principalmente en la región. En palabras de una pobladora:

Antes éramos un pueblito perdido, recién ahora a partir de la historia tenemos otra posición. Siento que la Asociación hizo un buen uso de ese recurso, con el turismo histórico cultural se puede levantar un poco el nombre. La gente hoy ubica a Villa Guillermina por La Forestal, por eso pienso que hay un reconocimiento a partir de la historia. (Joven, trabaja como animadora cultural en el Campamento Cultural Corazón de Quebracho, 2009)

Podemos advertir que la gestión del proyecto turístico ha producido cambios importantes en la manera de recuperar y representar el pasado industrial, con el propósito de darse a conocer y esperar ser reconocidos por otros como una comunidad que reconoce sus orígenes en la actividad industrial. En un esfuerzo por construir y reforzar lazos de continuidad con ese pasado. Es en este sentido que, como sostienen Martín y Rotman (2005, p. 12): “[...] la preservación del patrimonio opera como recurso de recuperación de memoria social, como un trabajo selectivo y transformador del pasado enfocando en la articulación entre pasado y presente".

En este programa turístico convergen diferentes actores sociales, agentes de las políticas públicas y pobladores, quienes atribuyen al patrimonio forestal diferentes sentidos. Advertimos que la sociedad civil se involucra activamente en el proyecto de puesta en valor del pasado forestal y genera estrategias puntuales para la activación patrimonial, articulando con los intereses del poder político provincial. En este sentido, como sostiene Prats (1998, p. 69) los agentes sociales 
“[...] para salir adelante, siempre deberán contar con el soporte, o cuanto menos, el beneplácito del poder. Sin poder podríamos decir que, en términos generales, no existe el patrimonio".

La concreción del proyecto de la ruta turística implica negociación constante entre los poderes públicos y la sociedad civil, es decir el sector de la sociedad civil que se constituyó como gestora del proyecto local. Cada parte persigue sus propios objetivos, y en la mutua dependencia aseguran el éxito de sus proyectos.

En el siguiente relato, un funcionario reflexiona sobre los objetivos que persigue la administración pública con la promoción de la ruta turística.

La idea del itinerario temático de los Pueblos Forestales es mostrar el trabajo industrial que se dio en un determinado lugar, y que hay que sacar de alguna manera conclusiones, y ver qué es lo que quedó. A nosotros nos interesa que se pueda conocer todo el proceso, cómo fue todo el proceso de industrialización y pos desindustrialización que fue muy conflictivo [...] En este caso, apuntamos a que el atractivo sea todo ese proceso laboral, la materialización de esa cultura, la forma de trabajo, de desarrollo, bueno mejor dicho de crecimiento, porque no fue un modelo de desarrollo sustentable. (Director de Desarrollo turístico de la provincia de Santa Fe, 2010)

Ahora bien, y como podremos apreciar más adelante, la propuesta de los promotores locales no se basa en una revisión crítica del pasado industrial. Por el contrario, la elección que hacen es evitar asociar el pasado con episodio conflictivos, violentos, traumáticos, como así también "sacar conclusiones" sobre las consecuencias que la explotación forestal tuvo en la región. De hecho, privilegian otra visión del pasado, rememoraran el trabajo y el bienestar social garantizado por una empresa extranjera. En síntesis, se enfatiza en la seguridad laboral y social como factores que caracterizaron a la comunidad forestal, o mejor dicho a la comunidad forestal urbana, y sobre esta selección de sentidos construyen la propuesta turística. 


\section{Museo un Espacio Social en Continua Construcción}

Museo y Campamento Cultural funcionan de manera articulada, fueron creados por un grupo de pobladores que desarrolló la propuesta turística en el escenario local. De hecho, además de los recorridos urbanos que realizan los visitantes - estudiantes, en los que observan antiguas construcciones del pueblo fábrica, la visita al museo es una de las atracciones más destacadas del itinerario turístico.

El museo representa para sus gestores la posibilidad de materializar no solo la visión que tienen de su historia, sino también de fortalecer el sentimiento de pertenencia estableciendo lazos de continuidad con el pasado forestal que custodian. Asimismo, es un lugar para trabajar la memoria, donde se narran episodios del tiempo pasado, y se transmite conocimiento a las nuevas generaciones. Como sostiene Sosa González (2014, p. 83):

No es posible hablar de museos sin memoria. Es la institución que funciona como su guardiana. Cualquiera fuera la selección que realice en sus exposiciones, opera siempre con los vestigios, rastros, fragmentos de una memoria que un grupo o comunidad desea colocar en el espacio museal.

En este contexto quienes impulsaron la creación del museo se propusieron preservar y difundir conocimientos vinculado a las vivencias personales del tiempo pasado, específicamente a las memorias de la época forestal. "Lo que nosotros queremos es contar la otra historia, la que no está en los libros, queremos contar lo que vivió la gente [...]" (Miembro de la Asociación e impulsor del proyecto de creación del museo, 2005).

Así, con la intención de comunicar las memorias de los protagonistas de ese tiempo se seleccionaron relatos de ex trabajadores forestales, considerados relevantes para la función del museo, esto es volver memorables algunos recuerdos otorgándoles identidad patrimonial.

De este modo, se llevó a cabo un trabajo de selección y organización de recuerdos que se expresa en el repertorio material del museo, como así también en la formalización de una narrativa legitimada en el carácter testimonial de los relatos del tiempo pasado. En síntesis, 
los gestores intentaron fijar una interpretación de la época forestal presentándola como versión representativa de los guillerminenses. Y el museo se constituyó, como afirma Bastías Sekulovic (2016, p. 205) en "lugar mediador entre lo íntimo y lo colectivo".

En esta propuesta los recuerdos de la época forestal respetan un orden cronológico marcado por largas temporalidades. El tiempo del origen, la época forestal que remite al período industrial, y post forestal, se trata de periodizaciones organizadas en un relato coherente, sin embargo, se omiten coyunturas históricas críticas que vendrían a cuestionar la propuesta comunicacional de bienestar social, así que no todas las memorias son agenciadas en el contexto museístico.

El acervo del museo está conformado por donaciones y préstamos de objetos del período forestal que fueron aportados por los pobladores. Las exhibiciones exponen objetos de trabajo, de la vida cotidiana, y muchas fotografías en las que algunos visitantes se reconocen y reconocen a familiares, compañeros, amigos, vecinos. A grandes rasgos el repertorio del museo se mantiene constante desde la fecha de su inauguración en el año 2004, cabe aclarar que desde ese año ha pasado por tres sedes. No obstante, en la última y actual sede, propiedad de la Asociación, la presentación museográfica da cuenta de transformaciones que operan en las representaciones sociales del pasado.

En la visita guiada por el museo se aprecian fotografías del fundador de la fábrica y del pueblo obrero. Otras de la fábrica de tanino, de obreros de fábrica y del puerto. Las imágenes ocupan un lugar relevante, pero también los objetos porque a través de ellos se pretende reconstruir la dinámica de la vida cotidiana del pueblo de trabajadores forestales. El guía en su relato enfatiza en las características del pueblo fábrica, y también en la provisión de bienes y servicios que proporcionaba la empresa como viviendas, hospital, clubes, cine, transporte, que se definen como "beneficios forestales". Esta categoría nativa es utilizada por los actores para explicitar que dichos beneficios se recibían de forma gratuita. Se podría complejizar el tema de la gratuidad, aunque no es el propósito en esta ocasión y basta con decir que el beneficio forestal es percibido por los actores como dación gratuita de la empresa, porque no exigía una retribución monetaria directa. 
La exposición del museo se estructura a base de dos ejes temáticos, trabajo y vida cotidiana del pueblo obrero, y en términos generales las exhibiciones se mantuvieron sin grandes modificaciones hasta el año 2012, cuando es trasladado a su nueva sede. Anteriormente, el relato comenzaba en el año 1904 con la fundación de la fábrica, y culminaba en el año 1952 con su cierre. Durante el recorrido se observa un trabajo cuidadoso tanto en la presentación estética del repertorio como en el guion museístico. Se transmiten determinados episodios del pasado considerados relevantes, y por lo tanto dignos de ser comunicados, y a la vez se omiten acontecimientos trágicos vinculados a la violencia empresarial. Sobre los hechos de represión, persecución, expulsión y ejecución de trabajadores durante las huelgas obreras se construye un silencio hermético que los gestores del museo no están dispuestos a quebrar. Porque el museo reivindica su versión apoyándose en la política del testimonio oral, y quienes producen esas fuentes orales, los testigos directos, no vivieron el período más violento que se desencadenó en la década de los años mil novecientos veinte.

Sin embargo, tampoco se pretende problematizar otros períodos del pasado visibilizando testimonios de quienes aún viven, pero tienen recuerdos disidentes con la versión oficial. De este modo, el museo construye un relato que silencia algunas memorias las que remiten a las condiciones de trabajo y de vida de los trabajadores del monte, al impacto ambiental que implicó la explotación a gran escala, a la crisis laboral y el consecuente despoblamiento de la zona. El pasado evocado en el museo deviene en un universo de seguridad laboral, bienestar y progreso social, exponente de civilización y modernidad asociado al capital internacional, y sobre estos tópicos se construye la narrativa.

Ahora bien, esta ausencia de una memoria crítica del pasado está relacionado con la forma en que los guillermineses quieren ser reconocidos por otros, y en ese sentido sostienen una línea argumentativa de memorias que dan cuenta del progreso y el bienestar social provisto por La Forestal. No obstante, no es un discurso desprovisto de críticas, aunque no se formulen explícitamente, porque lo que se pone de manifiesto en la narrativa museística es la ausencia histórica del Estado en la formación de las poblaciones forestales. Ausencia que se recrudece más luego del cierre de la fábrica. La narrativa del museo interpela 
a ese otro ausente en el pasado, a quien le demanda intervención y compromiso en el presente.

El museo surgió como espacio comunitario gestionado por un grupo de pobladores que desde una perspectiva local procuraron "rescatar" recuerdos del tiempo pasado compartidos en entornos privados y brindarles una plataforma pública para la difusión. Lo que explica la participación activa de la población con donaciones efectuadas al museo en el momento de su conformación. El objetivo de los emprendedores fue generar otra narrativa sobre el pasado, diferente a la que transmitió la historia oficial, en la que todos los guillerminenses pudieran sentirse representados. Pero en el armado del guion museístico, los gestores culturales llevaron a cabo el trabajo de recuperación, interpretación, y jerarquización de memorias, y se fue configurando un relato único del pasado, una versión local hegemónica que se legitima por su carácter testimonial, claro está que no todos los testimonios tienen un lugar en el museo. En este sentido y como sostiene Pollak (2006, p. 41) "[...] cada vez que una memoria está relativamente constituida realiza un trabajo de mantenimiento, de coherencia, de unidad y continuidad de la organización".

En los testimonios que recopilé durante mi trabajo de campo, en general, los trabajadores rurales rememoran sus experiencias pasadas recuperando episodios positivos asociados al trabajo, la juventud, el compañerismo, sin embargo, esto no anula los recuerdos dolorosos de la vida en los obrajes forestales. Como se pone de manifiesto en el siguiente relato.

[...] mire doña yo a veces no quiero recordar, porque pasamos tan mala vida en los obrajes. Trabajo teníamos, eso sí, pero vivíamos como esclavos. A la compañía [se refiere a La Forestal] no le importa nada la vida de los peones, acá en el pueblo la gente vivía bien, pero nosotros éramos los más desprestigiados de todos [...] (Ex trabajador rural, 2009)

Ahora bien, cómo se conjugan estos recuerdos con otros que están presentes en el museo y que rememoran el tiempo pasado de seguridad laboral y bienestar social.

La Forestal acá hizo todo, las viviendas, los clubes, el hospital, escuelas, todo lo que se necesita para la subsistencia de un pueblo. Si usted venía 
a trabajar para la Forestal le daban enseguida la vivienda, y si faltaba vivienda se la construían. En todas estas casas hemos vivido toda la vida gratis, a nosotros no nos cobró nada La Forestal, nunca. (Ex trabajador fabril, 2009)

Considero que la exhibición con la que culmina la visita guiada escenifica de algún modo la complejidad que suscita para los pobladores, en el contexto de turismo cultural, la activación del pasado. En un espacio reducido, casi escondido en un rincón con escasa iluminación, se encuentran algunos objetos y fotografías que testimonian la vida de los trabajadores rurales. Un cartel con la leyenda "Allá en el monte" parecería expresar en términos sintomáticos la constante confrontación entre las memorias de trabajadores fabriles y rurales. En este sentido, se intenta generar un distanciamiento ideológico con esos recuerdos para resolver, aunque de forma momentánea, la incomodidad que provocan algunos recuerdos.

En mi última visita al museo me acompañó un miembro fundador de la Asociación quien ofició de guía en esa ocasión, porque quería mostrarme la nueva sede y las modificaciones que hicieron. Cuando estábamos en la exhibición sobre el trabajo rural, ya terminando el recorrido, me dice: "Esto no sabemos bien todavía dónde ponerlo". Interesante metáfora de las tensiones que generan algunas memorias a la narrativa institucional.

El trabajo del obraje forma parte del universo forestal que se "rescata" y en tal sentido reclama representatividad en el museo. Sin embargo, la narrativa que se construye en torno a la exhibición del trabajo rural se circunscribe a una descripción funcional de los objetos, sin pretender dimensionar las condiciones de trabajo y de vida de los trabajadores forestales del monte, en esta instancia se deja de hablar de las experiencias de los sujetos en el tiempo pasado y la atención se centra en los objetos. Pero como sabemos los objetos son mudos, o mejor dicho "[...] hablan por sí mismos sólo a aquéllos que los pueden incorporar a una red de conocimientos previos" (Dujovne, 1995, p. 15). En este caso, parecería que para tolerar la presencia material de esos objetos que remiten a un pasado que incomoda recordar por las tensiones que genera con el relato de bienestar social, es necesario 
recurrir a la estrategia de la abreviación y de los silencios. En otras palabras, cuando se incursiona en terrenos ríspidos la estrategia utilizada es abreviar y/o silenciar recuerdos disidentes.

Por otro lado, en la actual sede del museo se han producido modificaciones que ponen de manifiesto el trabajo dinámico de la memoria, a la vez que algunos recuerdos continúan siendo silenciados, otros son agenciados. La memoria como sostiene Gordillo (2006, p. 6): “[...] ]es siempre una construcción hecha a partir de las condiciones y experiencias del presente: esto es, es una práctica que gira en torno a núcleos de significado importantes para quienes recuerdan".

En la sede actual del museo se advierte la construcción de nuevos sentidos sobre el pasado que se expresan a través de ampliaciones en las muestras, y modificaciones en el relato. Anteriormente la exhibición iniciaba con una serie de fotografías del fundador de la fábrica y su familia, actualmente la muestra se inicia con la narrativa de las primeras poblaciones indígenas que habitaban el territorio antes de la llegada de los empresarios extranjeros. De este modo, el origen de Villa Guillermina trasciende el inicio industrial, los primeros habitantes no fueron los extranjeros, sino los indígenas. Además, y eso también resulta interesante, el pasado rememorado no finaliza con el cierre de la fábrica de tanino y el éxodo masivo de población en 1952, como sucedía anteriormente, sino que continúa con una exposición de fotografías que referencian actividades productivas que comenzaron a desarrollarse luego del colapso de la industria tánica.

Estas intervenciones, en la sede actual, dan cuenta de cambios de posicionamiento social de los gestores culturales. La opción de ampliar el relato incorporando nuevos referentes pone de manifiesto que el trabajo de memoria, de selección y organización, es dinámico y está en continua redefinición. Los cambios producidos en las exhibiciones se orientan a reforzar la relación con la territorialidad, con el sentido de pertenencia a un lugar, también con el reconocimiento de un origen en común, y una trayectoria compartida. En definitiva, el sentimiento de identidad de un colectivo social que, con todas sus contradicciones y diferencias, se identifica con la tradición forestal. 


\section{A Modo de Cierre}

En el presente estudio de caso apreciamos la emergencia del fenómeno de valorización del pasado vinculado a la emergencia de actividades turísticas, en el marco de políticas públicas que impulsan el turismo cultural como factor de activación de economías regionales. En este escenario la memoria colectiva se erige en el principal elemento para la construcción singular del atractivo turístico. Y como pudimos observar en el campo social intervienen varios actores movilizados por intereses diferentes, no obstante, concuerdan en algo, la conversión del pasado en producto comercializable.

En el proceso de patrimonialización de memorias los gestores locales desempeñan un rol importante, en el trabajo de selección, ordenación y jerarquización, intervienen con el propósito de construir y formalizar un relato sobre el tiempo pasado que estimule sentimientos de autovaloración y de orgullo, y a la vez permita un uso turístico. En ese marco se inscribe el museo, concebido por sus emprendedores como espacio físico y simbólico, representativo de la identidad de una comunidad. Pero no es un lugar neutral, el museo habla sobre el pasado, pero más sobre el presente, o mejor dicho sobre cómo sectores sociales usan el pasado atendiendo a los intereses y propósitos del presente.

El museo es un campo de tensión entre memorias presentes y ausentes, entre lo dicho y lo no dicho, desde ese lugar controversial sus gestores construyen una propuesta para los guillerminenses y para los otros, los visitantes. La imagen de un pueblo fantasma es parte del pasado, Villa Guillermina se identifica con "Corazón de Quebracho", con la vitalidad y la fortaleza, con la vida que resiste a todo embate y se abre camino más allá de las adversidades. Probablemente este es el mensaje que más les interese comunicar y la posición que quieren asumir en el presente. Como reflexionaba un poblador: "Los pueblos forestales nos sentimos distintos, orgullosos, porque tenemos nuestra propia historia. Historia de sobrevivir, sobrevivir y trabajar" (Entrevista, 2009). 


\section{Notas}

1 Candau (1998, p. 71) plantea que con el tiempo las personas van atenuando el costado desagradable de ciertos recuerdos a través de abreviaturas y omisiones.

2 Explotación foresto industrial consistió en la actividad extractiva del recurso forestal Schinopsis balansae, quebracho colorado, y en el procesamiento industrial de la materia prima para la obtención de tanino. Producto que luego se exportaba a Europa y Estados Unidos.

3 Obraje funcionó como una unidad de organización del trabajo. Agrupaba a trabajadores, obrajeros, especializados en la tala y preparación de la madera de quebracho colorado para el proceso industrial.

4 Con esta denominación local se designa el espacio geográfico hábitat del quebracho colorado y otras especies. Además, se enfatiza en la condición natural del lugar, en oposición a lo urbano.

\section{Referências}

AGUILAR CRIADO, Encarnación. Patrimonio y globalización: el recurso cultural en las Políticas de Desarrollo Europeas. Cuadernos de Antropología Social, Buenos Aires, n. 21, p. 51-69, 2005.

BALAZOTE, Alejandro; RADOVICH, Juan Carlos; PRESTA, Susana. Inversión y desinversión: consideraciones para el análisis de sistemas de producción a término. Espacios, Tiempos y Sociedades, Luján: División Análisis Socioeconómico y Cultural. Departamento de Ciencias Sociales, n. 1, p. 47-58, 2009.

BASTÍAS SEKULOVIC, Malena. Del relato oficial a la recepción de los visitantes: análisis de la puesta en escena del pasado reciente en el Museo de la Memoria y los Derechos Humanos de Chile. In: ARRIETA URTIZBEREA, Iñaki (ed.). Lugares de memoria traumática. Bilbao: Universidad de País Vasco, 2016. p. 199-219.

BITLLOCH, Eduardo, SORMANI, Horacio. Los enclaves forestales en la región Chaqueña-Misionera. Ciencia Hoy, Buenos Aires, v. 7, n. 37, p. 41$52,1997$.

CANAU, Jöel. Memoria e identidad. Buenos Aires: Del Sol, 2008.

DUJOVNE, Marta. Entre musas y musaraña: una visita al museo. Buenos Aires: Fondo de Cultura Económica, 1995.

ECKERT, Cornelia. Memoria e trabalho: etnografía da duração de uma comunidade mineiros de carvão (La Grand-Combe, França). Curitiba: Appris, 2012.

GORI, Gastón. La Forestal. La tragedia del quebracho colorado. Buenos Aires: Eudeba, 1999. 
GORDILLO, Gastón. En el Gran Chaco. Antropologías e historias. Buenos Aires: Prometeo, 2006.

HERNÁNEZ RAMÍREZ, Javier. Los caminos del patrimonio. Rutas turísticas e itinerarios culturales. Pasos. Revista de Turismo y Patrimonio Cultural, [S.l.], v. 9, n. 2, p. 225-236, 2011.

JELIN, Elizabeth. Los trabajos de la memoria. Madrid: Siglo XXI, 2002. MARTÍN, Alicia; ROTMAN, Mónica. Presentación. Cuadernos de Antropología Social. Buenos Aires, n. 21, p. 7-15, 2005.

POLLAK, Michael. Memoria, olvido, silencio la producción social de identidades frente a situaciones límites. La Plata: Al Marge, 2006.

PRATS, Llorenç. El concepto de patrimonio cultural. Política y Sociedad, Madrid, n. 27, p. $63-76,1998$.

SOSA GONZÁLEZ, Ana María. El museo de la memoria de Uruguay. Algunas reflexiones en torno a los procesos de patrimonialización de memorias traumáticas. Clepsidra. Revista Interdisciplinaria de Estudios sobre Memoria, Buenos Aires, n. 2, p. 80-101, 2014.

Recebido em 17/05/2018

Aceito em 19/09/2018

Este texto está publicado sob uma Licença Creative Commons - Atribuição-NãoComercialCompartilhaIgual 4.0 Internacional - CC BY NC AS.

Mais detalhes em: https://creativecommons.org/licenses/by-nc-sa/4.0/deed.pt_BR 